\title{
Tamoxifen Attenuates Pulsatile Growth Hormone Secretion: Mediation in Part by Somatostatin*
}

\author{
GLORIA SHAFFER TANNENBAUM $\dagger$, WENDY GURD, MARTINE LAPOINTE, AND \\ MICHAEL POLLAK \\ Departments of Pediatrics, Neurology and Neurosurgery (G.S.T.), Medicine, and Oncology (M.P.), McGill \\ University; the Neuropeptide Physiology Laboratory, McGill University-Montreal Children's Hospital \\ Research Institute (G.S.T.), and the Lady Davis Research Institute of the Jewish General Hospital (M.P.), \\ Montreal, Quebec, Canada H3H 1 P3
}

\begin{abstract}
Tamoxifen, a partial competitive antagonist to the estrogen receptor, is a potent inhibitor of the proliferation of experimental mammary carcinoma in the rat and is widely used clinically in the treatment of breast cancer. Blockade of estrogen receptors present on neoplastic cells represents the classic mechanism of action of tamoxifen, but the drug has a variety of other actions that may contribute to its antiproliferative properties. While it is recognized that estrogens play an important role in modulating pulsatile $\mathrm{GH}$ release, the effect of antagonists to sex steroid receptors on GH secretory dynamics has not previously been described. In the present study we examined the effect of tamoxifen on pulsatile GH secretion in free-moving adult male and female rats. The drug, when administered in a manner previously shown to be associated with antineoplastic activity, caused a marked suppression of the amplitude of spontaneous $\mathrm{GH}$ secretory bursts and significantly reduced mean 6 -h plasma $\mathrm{GH}$ levels in both sexes compared to
\end{abstract}

those in their respective peanut oil-injected controls. Inhibition of spontaneous GH pulses persisted for up to 7 weeks after tamoxifen administration in both sexes. Immunoneutralization of endogenous somatostatin in tamoxifen-treated male rats completely restored both GH pulse amplitude (121.6 \pm 9.5 vs. 62.5 $\pm 13.5 \mathrm{ng} / \mathrm{ml}$ in tamoxifen-treated rats given normal sheep serum; $P<0.02)$ and mean 6 -h plasma GH levels $(53.3 \pm 6.6$ vs. $17.9 \pm 3.6 \mathrm{ng} / \mathrm{ml}$ in normal sheep serum-treated rats; $P<0.01$ ) to levels observed in our peanut oil-injected controls. These results demonstrate that 1) tamoxifen has potent inhibitory effects on pulsatile GH secretion; and 2) the blunting of GH pulse amplitude by tamoxifen is mediated at least in part by increased release of endogenous somatostatin. These findings motivate further investigation of the clinical significance of tamoxifen-induced suppression of GH secretion in relation to the antineoplastic activity of this commonly used drug.
$\mathrm{T}$ AMOXIFEN is a nonsteroidal partial competitive antagonist to the estrogen receptor (ER) that is widely used clinically because of its demonstrated efficacy in the adjuvant and palliative treatment of breast cancer (for review, see Ref. 1). In humans, the principle mechanism of action of the drug is thought to involve direct inhibition of estrogen binding to ERs present on neoplastic cells. There is evidence that at the cellular level such blockade may involve inhibition of estrogenstimulated proliferation of human breast cancer cells via stimulation of autocrine inhibitory loops involving transforming growth factor- $\beta$ (2), inhibition of autocrine stim- ulation by transforming growth factor- $\alpha$ (3), and modulation of responsitivity to insulin-like growth factor-I (IGF-I) (4). When tamoxifen is administered systemically, important sequelae resulting from the activity at ERs in certain nonneoplastic tissues also occur. Examples of such actions include inhibition of estrogen-stimulated PRL secretion (5), alterations in gonadotropin levels $(6,7)$, and inhibition of estrogen-stimulated rises in uterine wet weight (8). More recent clinical studies have demonstrated clinically useful effects of the drug on serum lipid profiles (9).

Sex steroids, in general, and estrogen, in particular, are known to have important and complex roles in modulating patterns of pulsatile GH release in both rats (1013) and humans $(14,15)$. The mechanisms underlying these effects have not been fully elucidated, but there is evidence that regulation takes place both at the level of the pituitary (16-18) and within the hypothalamus, where sex steroids influence the expression of somatostatin (SRIF) $(19,20)$ and GH-releasing hormone (GHRH) (21) genes. However, the effect of antagonists 
to sex steroid receptors on $\mathrm{GH}$ secretion has not been studied to date. The present investigation was, therefore, undertaken to determine whether tamoxifen, when administered to the rat in a manner previously demonstrated to be associated with antineoplastic activity (22), influences GH secretory dynamics.

\section{Materials and Methods}

Animals and experimental procedure

Adult male (254-308 g) and female (217-233 g) SpragueDawley rats were obtained from Charles River Canada (St. Constant, Quebec, Canada) and individually housed on a 12 -h light, 12-h dark cycle (lights on at $0600 \mathrm{~h}$ ) in a temperature (22 $\pm 2 \mathrm{C}$ )- and humidity-controlled room. Chronic intracardiac venous cannulae were implanted under sodium pentobarbital [50 mg/kg, ip (males) and $35 \mathrm{mg} / \mathrm{kg}$, ip (females)] anesthesia, using a previously described method (23). After surgery, each rat was injected im with $0.3 \mathrm{cc}$ (males) or $0.2 \mathrm{cc}$ (females) penicillin $\mathrm{G}(300,000 \mathrm{IU} / \mathrm{ml})$ and placed directly in an isolation test chamber with Purina rat chow (Ralston-Purina, St. Louis, MO) and tap $\mathrm{H}_{2} \mathrm{O}$ available ad libitum. Body weight was monitored daily, and the animals were sampled when body weight returned to preoperative levels (usually within 5-7 days). On the test day, food was removed $1.5-2 \mathrm{~h}$ before sampling.

In the first series of experiments, we studied the effect of tamoxifen on spontaneous $6-\mathrm{h}$ GH secretory profiles at various times after injection in both male and female rats. Tamoxifen (free base) was obtained from Sigma Chemical Co. (St. Louis, MO) and administered using a dose and route previously shown to have inhibitory effects on 7,12-dimethylbenz(a)anthracene (DMBA)-induced mammary tumors (22). Briefly, tamoxifen was dissolved in ethanol and added to peanut oil, after which the ethanol was evaporated under nitrogen using a $60 \mathrm{C}$ water bath. The rats were injected sc with $5 \mathrm{mg}$ tamoxifen in $0.2 \mathrm{ml}$ peanut oil once daily, at $1600 \mathrm{~h}$, on 2 consecutive days. Control rats were sc administered $0.2 \mathrm{ml}$ peanut oil at the same time points. Blood samples $(0.35 \mathrm{ml})$ were withdrawn every 15 min for 6 -h periods $(1000-1600 \mathrm{~h}$ ) beginning $18 \mathrm{~h}$ after the second injection of either tamoxifen or peanut oil. Subsequent samplings were performed at weekly intervals up to 7 weeks after the injections. All blood samples were immediately centrifuged, and the plasma was separated and stored at $-20 \mathrm{C}$ for subsequent assay of GH. The red blood cells were resuspended in normal saline and returned to the animal after removal of the next blood sample to avoid hemodynamic depletion.

In the second series of experiments, designed to assess the role of endogenous SRIF in mediating tamoxifen's effects on GH release, one group of tamoxifen-injected male rats $(5 \mathrm{mg} /$ $0.2 \mathrm{ml}$ at $1600 \mathrm{~h}$ on 2 consecutive days) was administered $2 \mathrm{ml}$ of a specific SRIF antiserum iv after removal of the first blood sample $18 \mathrm{~h}$ after the second tamoxifen injection. A second group of tamoxifen-treated male rats served as controls and received $2 \mathrm{ml}$ normal sheep serum (NSS) at the same time point. The SRIF antiserum was the same as that used in our previous passive immunization studies $(24,25)$. Blood samples were withdrawn every $15 \mathrm{~min}$ from 1000-1600 h.

\section{GH RIA}

Plasma GH concentrations were determined in duplicate by double antibody RIA, using materials supplied by the NIDDK Hormone Distribution Program (Bethesda, MD). The averaged plasma GH values are reported in terms of the $\mathrm{GH}$ reference preparation ( $\mathrm{rGH}$ RP-2). The standard curve was linear between $0.62-320 \mathrm{ng} / \mathrm{ml}$. The intra- and interassay coefficients of variation were $7.6 \%$ and $9.6 \%$, respectively, for duplicate samples of pooled plasma containing a mean $\mathrm{GH}$ concentration of $7.4 \mathrm{ng} / \mathrm{ml}$.

\section{SRIF binding of plasma after SRIF antiserum administration}

The SRIF binding of plasma from rats treated with SRIF antiserum and NSS was assessed hy determining the ability of aliquots of plasma obtained 1-2 min before and 15, 180, and $360 \mathrm{~min}$ after the injections to bind $\left[{ }^{125} \mathrm{I}_{\mathrm{T}} \mathrm{Tyr}_{1}\right.$-SRIF. Plasma samples from each rat were diluted 1:100 in the SRIF RIA assay buffer, and binding to labeled SRIF was determined under conditions routinely used for RIA of SRIF (26).

\section{Statistical analysis}

The plasma GH profiles of individual rats in all groups were analyzed using the Cluster analysis program for endocrine pulse detection (27). Briefly, a $t$ statistic between $3.2-4.1$ was selected to maintain a maximal false positive rate less than or equal to $1 \%$ by using a test cluster size of one in the prepeak nadir, peak, and postpeak nadir. Student's $t$ test was used for statistical comparisons between experimental groups. $P<0.05$ was considered significant.

\section{Results}

\section{Effects of tamoxifen on spontaneous $6-h$ GH secretory profiles}

Figure 1 illustrates individual representative plasma GH profiles in a peanut oil-injected control male rat (18 $\mathrm{h}$ postinjection) compared to those in tamoxifen-treated rats $18 \mathrm{~h}, 2$ weeks, and 7 weeks after injection. Control animals exhibited the typical pulsatile pattern of $\mathrm{GH}$ secretion; two episodes of $\mathrm{GH}$ release were evident during the 6 -h sampling period, with most peak $\mathrm{GH}$ values above $130 \mathrm{ng} / \mathrm{ml}$ and intervening trough levels below $1.2 \mathrm{ng} /$ ml. Eighteen hours after tamoxifen administration, there was a marked suppression of the amplitude of the spontaneous GH surges. Cluster analysis of GH secretory dynamics at this time point (Fig. 3) showed that tamoxifen treatment resulted in a 2 -fold decrease in $\mathrm{GH}$ peak amplitude $(58.4 \pm 12.7$ vs. $126.7 \pm 9.1 \mathrm{ng} / \mathrm{ml} ; P<0.01)$ and a significant suppression of overall mean 6 -h plasma GH level $(20.8 \pm 2.0$ vs. $35.7 \pm 4.6 \mathrm{ng} / \mathrm{ml} ; P<0.02)$ compared to that in peanut oil-injected controls, but did not significantly alter the GH nadir $(1.6 \pm 0.3$ vs. $1.2 \pm$ $0 \mathrm{ng} / \mathrm{ml})$ or $\mathrm{GH}$ peak frequency $(4.0 \pm 0.7 \mathrm{vs} .2 .8 \pm 0.5$ peaks $/ 6 \mathrm{~h}$ ). Tamoxifen-treated animals continued to exhibit suppressed GII pulses and reduced mean 6 -h plasma 


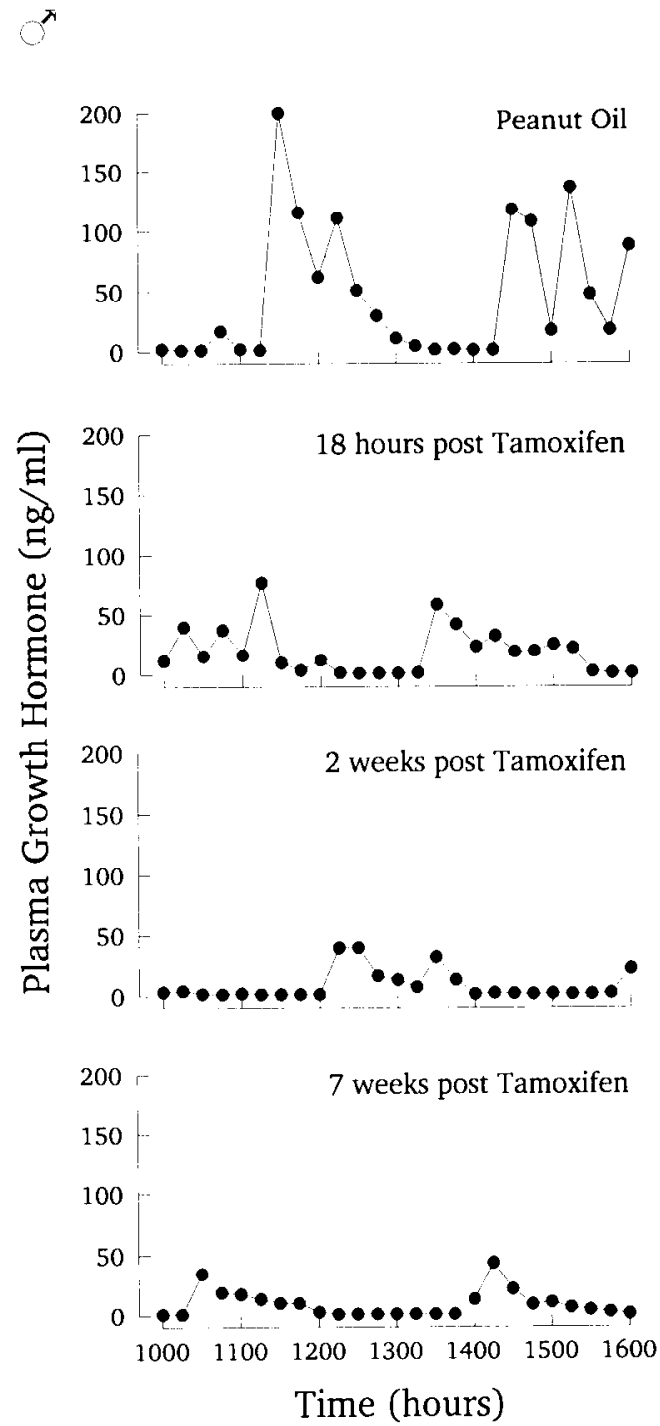

FIG. 1. Individual representative 6 -h plasma $\mathrm{GH}$ profiles in a peanut oil-injected control male rat compared to those in tamoxifen-treated male rats at varying times after injection. The sc administration of tamoxifen (two doses of $5 \mathrm{mg}$, sc) resulted in a marked attenuation of the amplitude of the spontaneous GH peaks $18 \mathrm{~h}$ after injection, and GH pulse amplitude remained severely suppressed for up to 7 weeks after treatment.

GH levels up to 7 weeks after the initial injections (Figs. 1 and 3 ).

Figure 2 shows individual representative plasma GH profiles in a peanut oil-injected female rat $(18 \mathrm{~h}$ postinjection) compared to those in tamoxifen-treated females at varying times after injection. The GH secretory profiles of control females were typically more erratic than those of control males (25) and showed more frequent, lower amplitude GH pulses separated by elevated nadirs. Eighteen hours after tamoxifen treatment, there was no significant alteration of $\mathrm{GH}$ secretory dynamics in female rats (Figs. 2 and 3). However, both GH pulse amplitude and mean 6 -h plasma $\mathrm{GH}$ levels were reduced 1-2 weeks
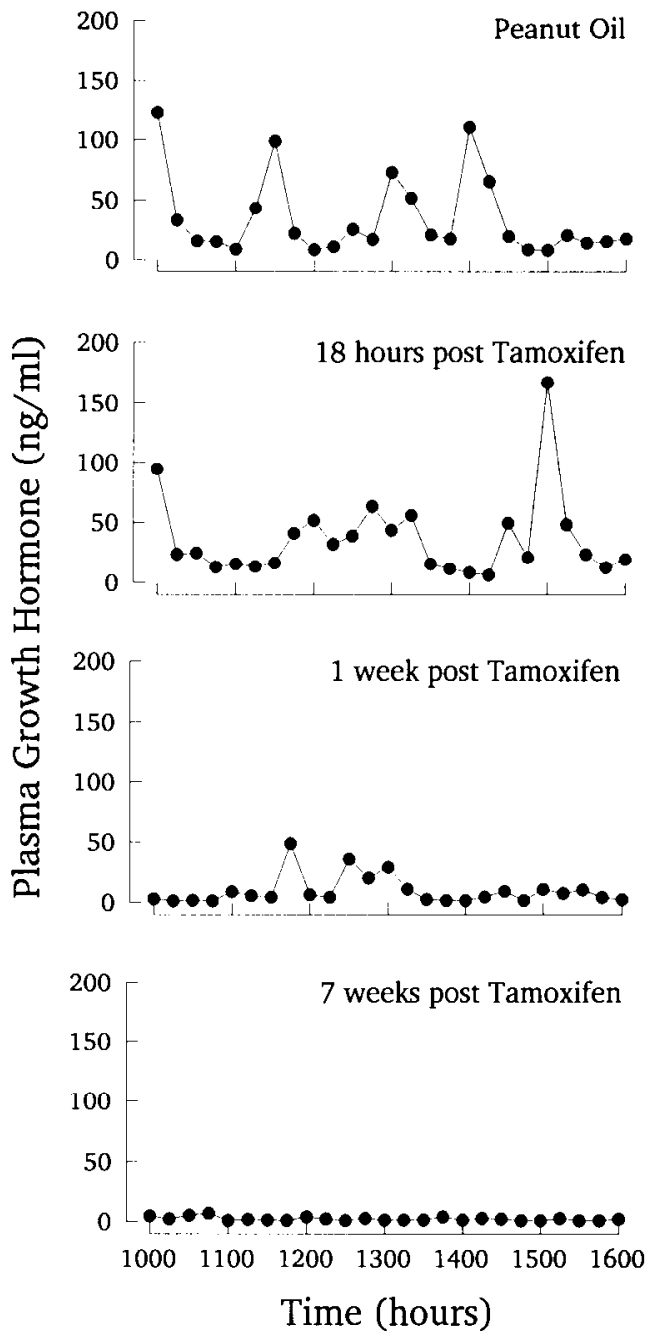

FIG. 2. Individual representative 6-h plasma $\mathrm{GH}$ profiles in a peanut oil-injected control female rat compared to those in tamoxifen-treated female rats at varying times after injection. Administration of tamoxifen (two doses of $5 \mathrm{mg}$, sc) caused a suppression of the $\mathrm{GH}$ pulse amplitude 1 week postinjection, which was maintained throughout the 7 -week observation period.

posttamoxifen administration (mean 6-h GH level, 11.6 \pm 1.2 vs. $27.7 \pm 3.6 \mathrm{ng} / \mathrm{ml} ; P<0.02)$ and remained significantly suppressed for up to 7 weeks after injection (Figs. 2 and 3). There was also a significant inhibition of GH nadir levels in tamoxifen-treated females compared to peanut oil-injected controls at $3-7$ weeks $(1.2 \pm 0 \mathrm{vs}$. $7.5 \pm 2.3 \mathrm{ng} / \mathrm{ml} ; P<0.02)$.

Effects of passive immunization with SRIF antiserum on GH secretory dynamics in tamoxifen-treated rats

Tamoxifen-treated male rats given NSS continued to show suppressed GH pulse amplitudes (Fig. 4A). Administration of SRIF antiserum to tamoxifen-pretreated rats rapidly reversed the blunting of $\mathrm{GH}$ peaks and resulted 
FiG. 3. Cluster analysis of GH secretory dynamics in male and female rats administered tamoxifen showed that tamoxifen caused a significant reduction in both $\mathrm{GH}$ peak amplitude and mean 6-h plasma GH level $18 \mathrm{~h}$ after injection in males, which was sustained for up to 7 weeks posttreatment. In females, the attenuation of GH peak amplitude and mean 6 -h plasma GH level was evident 1-2 weeks posttreatment and persisted for up to 7 weeks. Each bar represents the mean $+\mathrm{SE}$; the number of animals in each group is shown in parentheses. a, $P<0.01 ;$ b, $P<0.001 ; \mathrm{c}, P<0.02$ (compared to their respective peanut oilinjected controls).

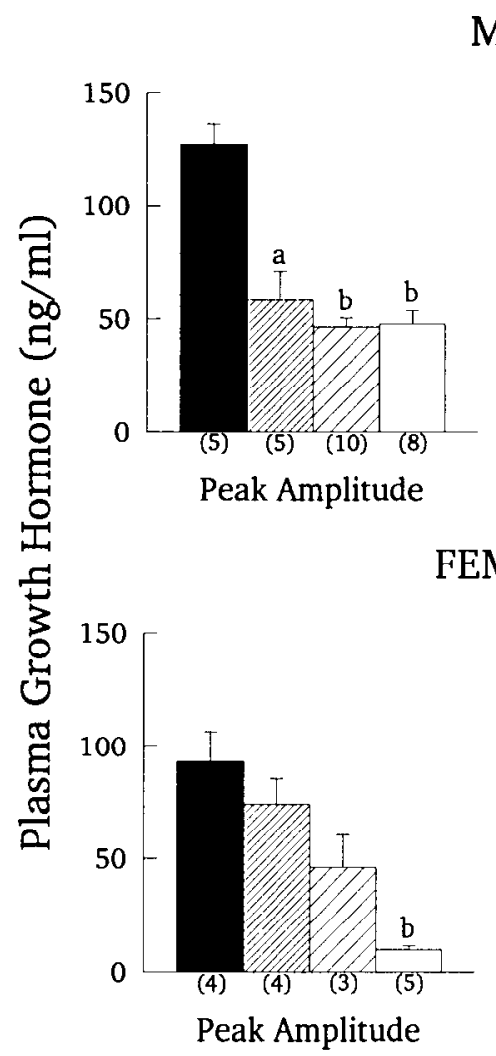

MALES

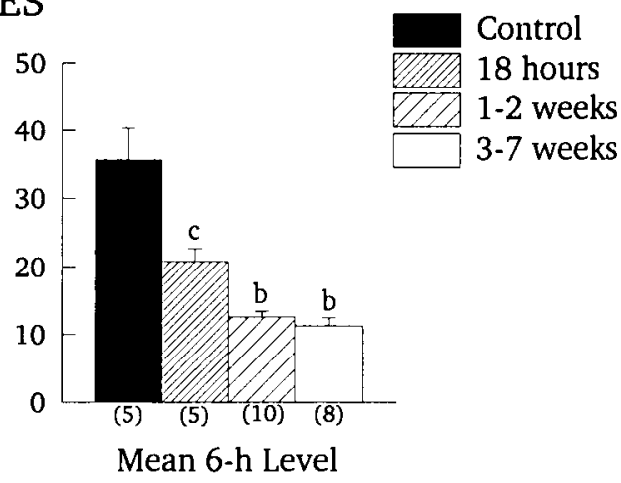

TEMALES

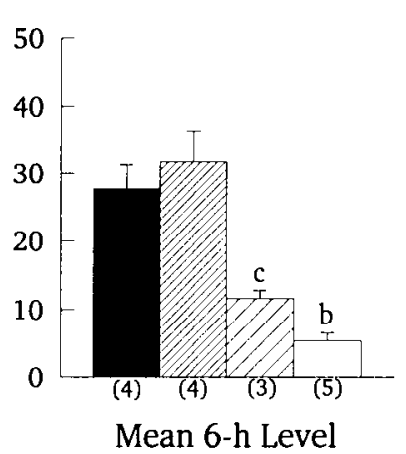

in a significant elevation of $\mathrm{GH}$ nadir levels (12.6 \pm 1.5 vs. $1.9 \pm 0.5 \mathrm{ng} / \mathrm{ml} ; P<0.001$; Fig. $4 \mathrm{~B})$. Cluster analysis (Fig. 5) showed that immunoneutralization of endogenous SRIF in tamoxifen-treated rats completely restored both GH pulse amplitude (121.6 \pm 9.5 vs. $62.5 \pm 13.5 \mathrm{ng} /$ $\mathrm{ml}$ in tamoxifen-treated rats given NSS; $P<0.02)$ and mean 6 -h plasma GH levels $(53.3 \pm 6.6$ vs. $17.9 \pm 3.6 \mathrm{ng} /$ $\mathrm{ml}$ in NSS-treated controls; $P<0.01$ ) to values as high as those observed in our peanut oil-injected male controls (see Fig. 3).

\section{SRIF binding of rat plasma after SRIF antiserum administration}

The mean ( \pm SE) SRIF binding levels of a 1:100 dilution of plasma of rats 1-2 min before and 15, 180, and 360 min after the injection of SRIF antiserum were $2.4 \pm$ $0.6 \%, 51.8 \pm 0.4 \%, 49.1 \pm 1.0 \%$, and $45.8 \pm 1.1 \%$, respectively. Plasma from NSS-treated animals showed no significant SRIF-binding activity at any of the time points tested.

\section{Discussion}

Although a large body of literature documents the important role of sex steroids in modulating the sexually dimorphic GH secretory patterns $(10-16)$, there have been no studies to date of the effects of estrogen and/or androgen receptor antagonists on GH secretory dynam- ics. In the present study we describe for the first time significant inhibitory effects of tamoxifen on GH secretion in the rat when the drug is administered in a manner previously shown to be associated with antineoplastic activity (22).

The results reported here clearly demonstrate that tamoxifen markedly attenuates the amplitude of the spontaneous GH secretory bursts as well as overall mean 6-h plasma GH levels as early as $18 \mathrm{~h}$ after administration. The inhibitory influence of tamoxifen, administered in the manner described, persists for at least 7 weeks in both male and female rats. This is probably a consequence of continuous slow release of the drug from the site of injection, rather than a delayed recovery from transient exposure to the drug. The 2-day sc injection protocol we employed has an inhibitory effect on DMBAinduced tumors that is measured in months (22), and active tamoxifen metabolites persist in the tissues for more than 8 weeks (28).

The effect of tamoxifen treatment on GH secretory dynamics observed in the present study has features in common with the effects of gonadectomy in adult male rats (13); both interventions suppress GH peak amplitude and mean 6-h plasma GH levels. There are some grounds for speculation that the drug, as a partial competitive antagonist to the $\mathrm{ER}$, might function as an agonist in the relatively low estrogen environment of the male. However, the GH secretory profiles of tamoxifen- 
Tamoxifen + Normal Sheep Serum
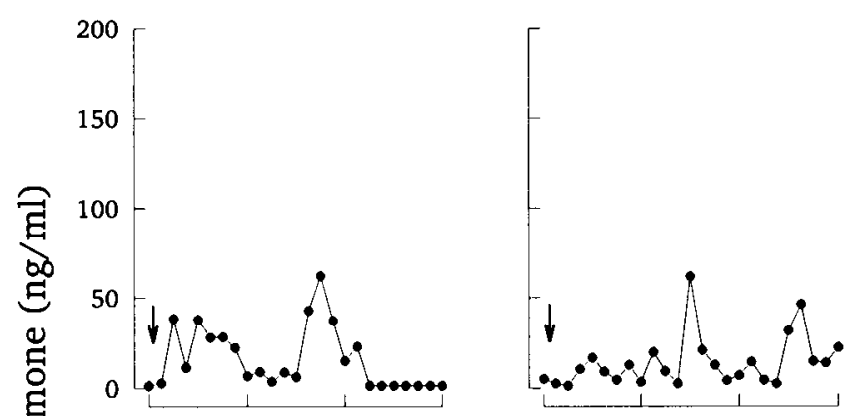

Tamoxifen + Somatostatin Antiserum

B
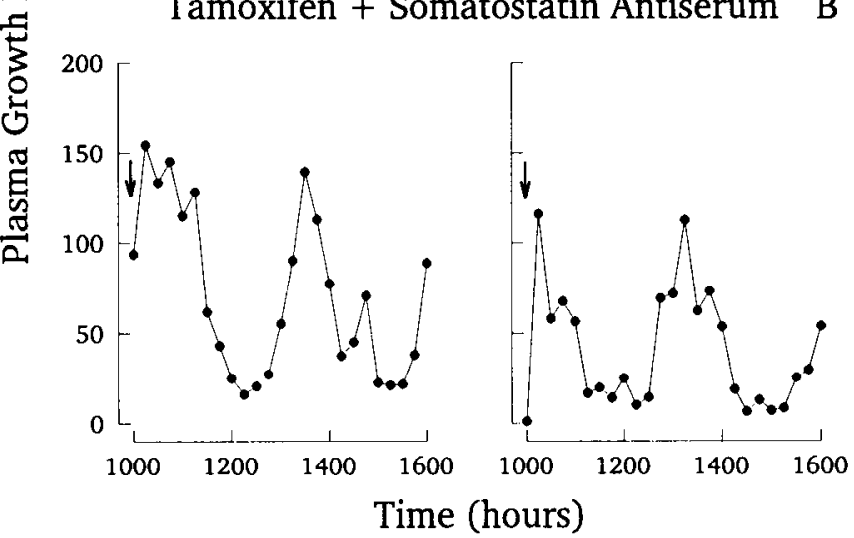

FIG. 4. Effects of passive immunization with SRIF antiserum on plasma GH profiles in tamoxifen-treated male rats (B) compared to those in tamoxifen-treated male rats given NSS (A). Administration of SRIF antiserum rapidly reversed the blunting of GH pulses observed in tamoxifen + NSS-treated rats. Arrows indicate the times of serum injections.

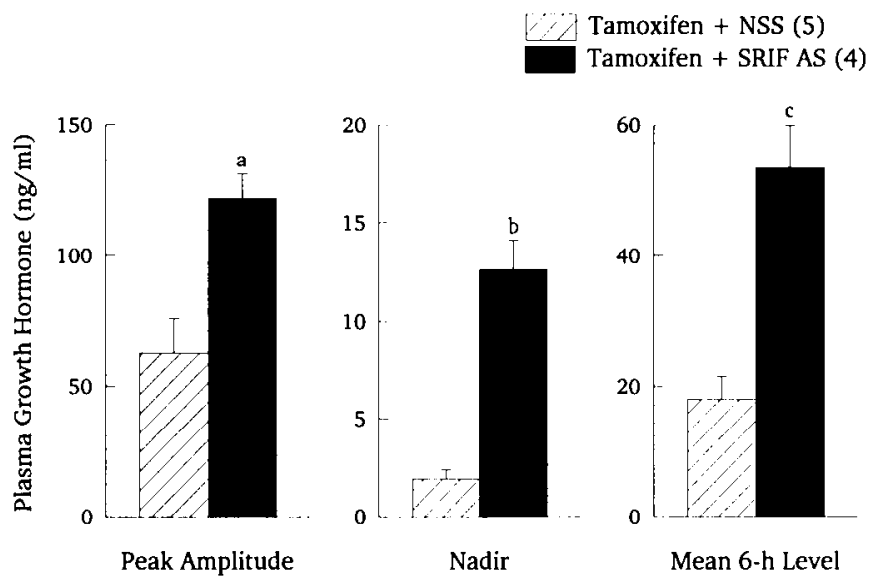

FIG. 5. Summary of effects of passive immunization with SRIF antiserum (AS) on GH secretory dynamics in tamoxifen-treated male rats. Immunoneutralization of endogenous SRIF completely restored the amplitude of the GH peaks and mean 6-h plasma $\mathrm{GH}$ levels to values similar to those observed in control male rats (see Fig. 3), in addition to significantly elevating the GH nadir. Each bar represents the mean $+\mathrm{SE}$; the number of animals in each group is shown in parentheses. $\mathrm{a}$, $P<0.02$; b, $P<0.001$; c $P<0.01$ (compared to tamoxifen + NSStreated control rats). treated rats show a pattern distinct from those observed when estradiol is administered to male rats; the major effect of estradiol in adult male rats is to elevate the GH nadir and increase GH peak frequency (13). In female rats, the effects of tamoxifen on GH secretory dynamics observed here are similar to those that we recently reported after ovariectomy of adult female rats, i.e. a decrease in GH nadir and mean 6-h plasma GH levels (29). Thus, the present data in females are consistent with the possibility that tamoxifen acts by blockade of ERs in the hypothalamic-pituitary axis, leading to effects similar to those seen when circulating estradiol levels are reduced by ovarian ablation.

The mechanisms by which tamoxifen exerts its effects on GH secretion are of interest. To determine if endogenous SRIF plays a role in mediating the inhibitory effect of tamoxifen on $\mathrm{GH}$ release, we carried out experiments involving passive immunization with anti-SRIF serum in tamoxifen-pretreated male rats. Immunoneutralization of endogenous SRIF reversed the tamoxifen-induced blunting of GH pulse amplitude and completely restored both the amplitude of the spontaneous $\mathrm{GH}$ surges as well as overall mean 6 -h plasma GH levels to values similar to those in our peanut oil-injected male controls. These results provide good evidence that the inhibitory effect of tamoxifen on GH secretion is mediated at least in part by increased release of endogenous SRIF. This finding is consistent with earlier reports indicating that SRIF gene expression in the rat hypothalamus can be influenced by sex steroids $(19,20)$. Moreover, recent morphological studies have demonstrated the presence of ERs in hypothalamic neurons in both the arcuate-ventromedial and preoptic areas (30), regions known to be involved in the control of GH secretion. Since a majority of these receptors was localized to a subpopulation of $\mathrm{GHRH}$ secreting cells, it is possible that in addition to actions on the somatostatinergic branch of the neuroendocrine axis, GHRH cells may also be a target for tamoxifen action. Finally, the possibility of direct inhibition by tamoxifen of GH synthesis and/or release at the level of the pituitary gland cannot be excluded. Indeed, recent tissue culture studies involving cultured pituitary cells in the presence of estrogens have demonstrated a reduction of GH output by tamoxifen (31).

The present study does not address the issue of whether the inhibitory effect of tamoxifen on GH secretion is related to the antineoplastic activity of the drug. However, it is of interest that there is some evidence in the DMBA rat mammary carcinoma model that at least part of the stimulatory effect of estrogens on neoplastic proliferation is dependent on pituitary factors $(32,33)$. In view of recent data suggesting that IGF-I is a potent mitogen for both DMBA-induced rat mammary tumors (34) and human breast cancers (reviewed in Ref. 35), the 
possibility that tamoxifen-induced suppression of the hypothalamic GH-IGF-I axis is related to the antineoplastic activity of the drug deserves investigation, as does the possibility of synergism between SRIF analogs and tamoxifen $(36,37)$. In addition, the suppressive effect of tamoxifen on GH secretion may also contribute to the effect of the drug on serum lipids (9), as GH administration has been associated with elevations of serum lipid levels (38).

While tamoxifen was originally prescribed only for patients with obvious metastases, use of the drug has become more widespread after clinical trials demonstrating the efficacy of adjuvant tamoxifen treatment for certain asymptomatic women after surgery for stage I or II breast cancer (1). Furthermore, trials involving thousands of women are currently planned to evaluate the worth of tamoxifen as a cancer preventative agent (1). While there have been no controlled clinical studies of the effect of tamoxifen on GH secretion, we recently reported a randomized blinded investigation that demonstrated a reduction of serum IGF-I levels in breast cancer patients receiving tamoxifen (35). The results reported here suggest that inhibition of $\mathrm{GH}$ secretion may explain this observation and motivate further investigation of the clinical significance of effects of tamoxifen on GH physiology.

\section{Acknowledgments}

We thank Evelyn Tetenes for technical assistance, and Julie Temko for skillful preparation of the manuscript. The generous supply of GH RIA materials from the NIDDK Hormone Distribution Program is gratefully acknowledged.

\section{References}

1. Lerner L, Jordan V 1990 Development of antiestrogens and their use in breast cancer. Cancer Res 50:4177-4189

2. Knabbe C, Lippman M, Wakefield L, Flanders KC, Kasid A, Derynck R, Dixon RB 1987 Evidence that transforming growth factor beta is a hormonally regulated negative growth factor in human breast cancer cells. Cell 48:417-428

3. Bates S, Davidson N, Valverius E, Freter CE, Dixon RB, Tam JP, Kudlaw JE, Lippman ME, Salomon DS 1988 Expression of transforming growth factor alpha and its mRNA in human breast cancer: its regulation by estrogen and its possible functional significance. Mol Endocrinol 2:543-555

4. Stewart A, Johnson M, May F, Westley B 1990 Role of insulinlike growth factors and the type I IGF receptor in the estrogenstimulated proliferation of human breast cancer cells. J Biol Chem 265:21172-21178

5. Jordan V, Koerner S, Robison C 1975 Inhibition of estrogenstimulated prolactin release by antiestrogens. J Endocrinol 65:151152

6. Jordan V, Fritz N, Tormey D 1987 Endocrine effects of adjuvant chemotherapy and long-term tamoxifen administration on nodepositive patients with breast cancer. Cancer Res 47:624-630

7. Ravdin P, Fritz N, Tormey D, Jordan V 1988 Endocrine status of premenopausal node-positive breast cancer patients following adjuvant chemotherapy and long-term tamoxifen. Cancer Res 48:1026-1029
8. Harper MJK, Walpole AL 1966 Contrasting endocrine activities of cis and trans isomers in a series of substituted triphenylethylenes. Nature 212:87-90

9. Love R, Newcomb P, Wiebe D, Surawicz T, Jordan VC, Carbone PP, Demets DL 1990 Effects of tamoxifen therapy on lipid and lipoprotein levels in postmenopausal patients with node-negative breast cancer. J Natl Cancer Inst 82:1327-1332

10. Jansson J-O, Edén S, Isaksson 01985 Sexual dimorphism in the control of growth hormone secretion. Endocr Rev 6:128-150

11. Jansson J-O, Frohman LA 1987 Inhibitory effect of the ovaries on neonatal androgen imprinting of growth hormone secretion in female rats. Endocrinology 121:1417-1423

12. Shulman DI, Sweetland M, Duckett G, Root AW 1987 Effect of estrogen on the growth hormone $(\mathrm{GH})$ secretory response to $\mathrm{GH}$ releasing factor in the castrate adult female rat in vivo. Endocrinology 120:1047-1051

13. Painson J-C, Thorner MO, Krieg RJ, Tannenbaum GS 1992 Shortterm adult exposure to estradiol feminizes the male pattern of spontaneous and growth hormone-releasing factor-stimulated growth hormone secretion in the rat. Endocrinology 130:511-519

14. Ho KY, Evans WS, Blizzard RM, Veldhuis JD, Merriam GR Samojlik E, Furlanetto R, Rogol AD, Kaiser DL, Thorner MO 1987 Effects of sex and age on the 24-hour profile of growth hormone secretion in man: importance of endogenous estradiol concentrations. J Clin Endocrinol Metab 64:51-58

15. Mansfield MJ, Rudlin CR, Crigler Jr JF, Karol KA, Crawford JD, Boepple PA, Crowley Jr WF 1988 Changes in growth and serum growth hormone and plasma somatomedin-C levels during suppression of gonadal sex steroid secretion in girls with central precocious puberty. J Clin Endocrinol Metab 66:3-9

16. Carlsson L, Eriksson E, Seeman H, Jansson J-O 1987 Oestradiol increases baseline growth hormone levels in the male rat: possible direct action on the pituitary. Acta Physiol Scand 129:393-399

17. Simard J, Hubert J-F, Hosseinzadeh T, Labrie F 1986 Stimulation of growth hormone release and synthesis by estrogens in rat anterior pituitary cells in culture. Endocrinology 119:2004-2011

18. Hertz P, Silbermann M, Even L, Hochberg Z 1989 Effects of sex steroids on the response of cultured rat pituitary cells to growth hormone-releasing hormone and somatostatin. Endocrinology 125:581-585

19. Werner H, Koch Y, Baldino Jr F, Gozes I 1988 Steroid regulation of somatostatin mRNA in the rat hypothalamus. $J$ Biol Chem 263:7666-7671

20. Chowen-Breed JA, Steiner RA, Clifton DK 1989 Sexual dimorphism and testosterone-dependent regulation of somatostatin gene expression in the periventricular nucleus of the rat brain. Endocrinology 125:357-362

21. Zeitler P, Argente J, Chowen-Breed JA, Clifton DK, Steiner RA 1990 Growth hormone-releasing hormone messenger ribonucleic acid in the hypothalamus of the adult male rat is increased by testosterone. Endocrinology 127:1362-1368

22. Jordan V 1976 Effect of tamoxifen on initiation and growth of DMBA-induced rat mammary carcinomata. Eur J Cancer 12:419 424

23. Tannenbaum GS, Martin JB 1976 Evidence for an endogenous ultradian rhythm governing growth hormone secretion in the rat. Endocrinology 98:562-570

24. Tannenbaum GS, Ling N 1984 The interrelationship of growth hormone (GH)-releasing factor and somatostatin in generation of the ultradian rhythm of GH secretion. Endocrinology 115:19521957

25. Painson J-C, Tannenbaum GS 1991 Sexual dimorphism of somatostatin and growth hormone-releasing factor signaling in the control of pulsatile growth hormone secretion in the rat. Endocrinology 128:2858-2866

26. Tannenbaum GS, Rorstad O, Brazeau P 1979 Effects of prolonged food deprivation on the ultradian growth hormone rhythm and immunoreactive somatostatin tissue levels in the rat. Endocrinology 104:1733-1738

27. Veldhuis JD, Johnson ML 1986 Cluster analysis: a simple, versatile, and robust algorithm for endocrine pulse detection. Am J Physiol 250:E486-E493 
28. Lien E, Solheim E, Ueland P 1991 Distribution of tamoxifen and its metabolites in rat and human tissues during steady-state treatment. Cancer Res 51:4837-4844

29. Painson, J-C, Tannenbaum GS 1990 L'ovariectomie et la testostérone masculinisent la sécrétion rythmique de l'hormone de croissance chez la rate adulte. Med Sci [Suppl 2] p 22A (Abstract)

30. Shirasu K, Stumpf WE, Sar M 1990 Evidence for direct action of estradiol on growth hormone-releasing factor (GRF) in rat hypothalamus: localization of $\left[{ }^{3} \mathrm{H}\right]$ estradiol in GRF neurons. Endocrinology 127:344-349

31. Malaab SA, Pollak MN, Goodyer CG, Direct effects of tamoxifen on growth hormone secretion by pituitary cells in vitro. Eur $\mathbf{J}$ Cancer, in press

32. Sterental A, Dominiguez JM, Weissman C, Pearson OH 1962 Pituitary role in the estrogen dependency of experimental mammary cancer. Cancer Res 23:481-485

33. Arafab B, Manni A, Pearson O 1980 Effect of hypophysectomy and hormone replacement on hormone receptor levels and the growth of 7,12-DMBA-induced mammary tumors in the rat. Endocrinology 107:1364-1369

34. Ruggeri B, Klurfeld D, Kritchevsky D, Furlanetto R 1989 Growth factor binding to 7,12-DMBA-induced mammary tumors from rats subject to caloric restriction. Cancer Res 49:4135-4141

35. Pollak M, Costantino J, Polychronakos C, Blauer S, Guyda H, Redmond C, Fisher B, Margolese R 1990 Effects of tamoxifen on serum IGF-I levels of stage I breast cancer patients. J Natl Cancer Inst 82:1693-1697

36. Pollak M, Polychronakos C, Guyda H 1989 Somatostatin analogue SMS 201-995 reduces serum IGF-I levels in patients with neoplasms potentially IGF-I dependent. Anticancer Res 9:889-892

37. Pagliacci MC, Tognellini R, Grignani F, Nicoletti I 1991 Inhibition of human breast cancer cell (MCF-7) growth in vitro by the somatostatin analog SMS 201-995: effects on cell cycle parameters and apoptotic cell death. Endocrinology 129:2555-2562

38. Moller A, Rasmussen LM, Thuesen L, Christiansen JS 1989 Impact of human growth hormone on plasma lipoprotein concentrations. Horm Metab Res 21:207-209 